the permanganate, and that, for laundry purposes, this coloration was of no consequence.

Subsequently, when the writer's report became available, ${ }^{1}$ the contention was made by a representative of one of the prominent alkali manufacturers that the pink color was due not to the presence of permanganate, but of a ferrate; and in order to settle definitely the whole matter, the absorption spectrum of the pink bleaching solution was compared with that of a solution of potassium permanganate of the same color intensity. The solution used was made four times the concentration $^{2}$ usually employed and, after all the precipitate had settled, a saccharimeter tube was filled with the clear pink solution. A similar tube was filled with potassium permanganate solution of same color intensity and the absorption spectra were compared; they were found to be identical. To compare the two more carefully, the two absorption spectra were brought in view at one time, by means of the comparison mirror, and the positions of the lines were shown to be exactly the same.

No attempt is made here to account for the presence of the trace of manganese in the bleaching powder, but the writer feels that he has offered positive evidence that the color of the pink bleaching solutions is due to the presence of sodium permanganate, and not of sodium ferrate, as some have maintained.

Mélon Instrtute of Industrial Research PITTSBURGH

\section{ON THE USE OF CERTAIN YEAST NUTRIMENTS IN BREAD-MAKING ${ }^{3}$}

By Henry A. Kohman, Charles Hoffman, Truman M. Godfrey, IAUTREN H. ASHE, AND ALFRED E. BLAKE Received June 7, 1916

The work in bread-making at the Mellon Institute was begun in rgr through the establishment of the Ward Fellowships and the results will now be published in a series of contributions.

One of the important problems studied in our bread investigations was the effect of certain mineral salts (such as are commonly found in natural waters) upon the fermentative activity of the yeast in breadmaking. It was found necessary by the Ward Baking Company (who operate bakeries in several cities) to change the quantity of yeast as well as the fermentation period of their dough batches in the different cities, in order to produce a standard product, or nearly so, even though all the raw materials used were identical (being purchased through a central office). Upon investigation it was found that variations in the activity of the yeast were due to the differences in the mineral content of the waters used for making the bread in these cities. In the work reported in this paper the effect of mineral salts found in natural waters upon the fermentative power of the yeast, as well as the quantity of yeast necessary for leavening purposes, has been given particular attention and

1 The conclusions were reported by bulletin to the Allegheny County Laundrymen's Exchange on April 17, 1916.

2. The solution of sodium hypochlorite was prepared with $40 \mathrm{~g}$. of commercial calcium hypochlorite, $40 \mathrm{~g}$. of soda ash, and $40 \mathrm{~g}$. of sodium bicarbonate, made up to a volume of $250 \mathrm{cc}$. with distilled water.

3 A paper presented in abstract by Henry A. Kohman at the Lrbana Meeting of the American Chemical Society, April 19, 1916. close investigation. The mineral substances contained in flour, milk, yeast and other raw materials for bread were investigated in detail also, using a large variety of combinations and proportions.

Of the large number of substances investigated. those that have a really significant effect upon the fermentation in bread are surprisingly few. The salts of the mineral acids, such as the chlorides, nitrites, nitrates and sulfates, exert practically no influence except when combined with a cation which in itself has an effect. The carbonates are especially common in natural waters and as a class are objectionable in bread, since they neutralize the acids of the dough and thus interfere with the progress of the fermentation. More particularly, the carbonates of magnesium and the alkali metals should be considered as being detrimental to the fermentation of the yeast.

The salts of potassium, particularly the phosphates, were expected to exert a decided influence on the fermentation of bread, because these compounds constitute such a large proportion of the ash of yeast and are mentioned so frequently in connection with alcoholic fermentation. However, the potassium salts were found to influence the fermentation of bread only very slightly, while the phosphates had no noticeable effect. This is to be explained, no doubt, by the fact that the ash of flour is rich in these salts, consisting of about one-third potash $\left(\mathrm{K}_{2} \mathrm{O}\right)$ and one-half phosphoric acid $\left(\mathrm{P}_{2} \mathrm{O}_{5}\right)$, which abundantly supplies the yeast.

Because of their common occurrence in natural waters, the salts of the alkaline earth metals were studied in detail, with surprisingly interesting results. The calcium salts, especially, are of common occurrence in water and it is around these that the most interesting restults presented in this paper center.

Besides the water problem, the utilization of stale bread was indicated as an important problem for research. One of the proposed methods for using stale bread comprised the cooking of the crumbs and then digesting with malt. The starches were thus transformed into sugars and the gluten remained in flakes which could be separated by filtration. From this gluten residue, by digesting with concentrated $\mathrm{HCl}$ in the ordinary way, glutamic acid hydrochloride was recovered in considerable quantities. The effect of the glutamic acid upon the parent substance, gluten, in bread was found to be a decidedly beneficial effect both upon the dough and upon the yeast.

\section{AMMONIUM SALTS}

Like many other acids, glutamic acid matures or ages the dough and, in addition, increases the gas production of the yeast. This accelerating effect tupon the yeast was observed in bread and likewise in fermenting cane sugar, dextrose, and malt extract. In fermentation of this kind other acids failed to increase the fermentation as did glutamic acid hydrochloride, so we were led to believe that it was not a matter of acidity but that glutamic acid hydrochloride owes its accelerating effect to its nitrogen content. With this idea in mind, we conducted baking experi- 
ments with other nitrogenous stubstances. Ordinary peptone, stuch as is used for culture media, as already known, accelerates alcoholic fermentation greatly but this substance is expensive and, accordingly, attention was directed toward cheaper materials which would accomplish a similar result. The salts of ammonium were found fully as efficient as peptone.

Before giving the experimental data, it should be said that during the course of this investigation, which extended over a period of several years, the conditions were changed from time to time; consequently, the results of any particular series of baking experiments can not be compared strictly with those of another, Every precaution was taken, however, to maintain the same conditions throughout each series, so that the individual loaves could be compared closely with the control and with each other. In each series of experiments the loaves were scaled, moulded, proofed and baked together. Therefore, when accelerators were added the loaves naturally had not all risen to the same height when they were placed in the oven, as they do in commercial baking practice. Consequently, the volumes given in the tables are an expression of the rate of fermentation rather than of the relative lightness or degree of expansion that may be obtained. For example, when there was, say, a ro per cent increase in volume noted with the use of an accelerator, it does not mean that the expansion was increased but merely that the rate of fermentation was increased by that amount. If the two loaves had been brought to the same degree of maturity and proofed to the same height in the pans, as is customary in baking practice, both loaves would have conformed to the standard size. In many bread laboratories, also, it is customary to proof all the loaves to the same height, especially when the volumes are taken to represent the expansion, as is the case in testing flours. In the experiments of this paper, however, all the loaves of each series were baked simultaneously, so the volumes should be interpreted as indicating the rate of the fermentation rather than the expansion of the loaves.

The following series of experiments will serve to illustrate the effect of ammonium sulfate upon the yeast in bread-making. A kilogram of flour was used in each batch.

\begin{tabular}{|c|c|c|c|c|c|}
\hline $\begin{array}{c}\text { BREAD } \\
\text { No. }\end{array}$ & $\underset{\left(\mathrm{NH}_{4}\right)_{2} \mathrm{SO}_{4}}{\operatorname{Gras}}$ & $\begin{array}{c}\text { LoAf } \\
\text { Ce. }\end{array}$ & $\begin{array}{c}\text { VoLUME } \\
\% \text { Increase }\end{array}$ & $\begin{array}{l}\text { Cc. Gas } \\
\text { in } 71 / 2 \mathrm{hrs} .\end{array}$ & $\begin{array}{c}\text { Per cent Gas } \\
\text { Increase }\end{array}$ \\
\hline 646 & 0.0 & 1630 & 0.0 & 292 & 0.0 \\
\hline 647 & 0.5 & $\begin{array}{r}1790 \\
1865\end{array}$ & $\begin{array}{r}0.8 \\
14.4\end{array}$ & $\begin{array}{l}311 \\
310\end{array}$ & $\begin{array}{l}6.5 \\
6.5\end{array}$ \\
\hline $\begin{array}{l}648 \\
649\end{array}$ & $\frac{1}{2} .5$ & $\begin{array}{l}1870 \\
\end{array}$ & $\begin{array}{l}14.4 \\
14.7\end{array}$ & 329 & 12.6 \\
\hline 650 & 3.5 & 1930 & 18.4 & 328 & 12.6 \\
\hline 651 & 4.5 & 1900 & 16.5 & 338 & 15.7 \\
\hline
\end{tabular}

Besides increasing the gas production and improving and securing a more uniform loaf volume, the ammonium sulfate improved the texture and the general uniformity and appearance of the bread. The gas production was estimated by taking a small portion ( $5 \circ \mathrm{g}$.) from each dough and collecting the gas evolved over a saturated solution of calcium chloride in Bunsen gas holders.

In a cane-sugar medium, ammonium sulfate also greatly increased the fermentative power of yeast.
A series of seven fermentation experiments was made. using $68 \mathrm{~g}$. of water, $\mathrm{x} .2 \mathrm{~g}$. of yeast and $6 \mathrm{~g}$. of sugar, with varying amounts of ammonium sulfate. The results were as follows:

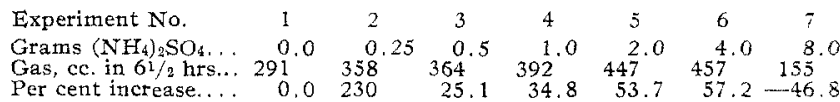

While readings were taken every half hour, the total gas produced will serve to illustrate the accelerating action of ammonium sulfate. It will be noted that $8 \mathrm{~g}$. has a marked retarding action.

Early in the research it was observed that the increased fermentation, due to ammonium sulfate, matured the doughs in a much shorter time. Bread fermented $31 / 2$ hrs. with the use of ammonium sulfate was practically as mature as the control bread in $4^{1 / 2}$ hrs. Obviously, then, this salt can be used for the production of bread in a shorter time. Ots first thought, one might infer that this action would be taken advantage of in increasing the output of a bakery; this, however, is not the case. The oven capacity, more than anything else, governs the productive power of a bakery. Although a short fermentation period is highly desirable in the bake shop, there is a limit beyond which it is not safe to go. Unforeseen delays are frequent in the daily operations, and since these often occur when the dough is already working, over-fermentation is the result. The shorter the fermentation period, the greater will be the overfermentation when delay occurs. In our opinion. according to present practices, the fermentation period should not be less than $4^{1 / 2}$ to $5 \mathrm{hrs}$. for hard wheat flours, excepting, of course, in special cases in which it is necessary to produce bread in a very short time to meet rush orders. In general, the increased fermentation due to the addition of ammonium sulfate can best be utilized by reducing the amount of yeast that is ordinarily required. The following series of baking experiments serves to illustrate the value of this salt in the diminution of yeast requirement:

\begin{tabular}{lcccc} 
& & \multicolumn{3}{c}{ Vol,UME OF LoAf (Cc.) } \\
Bread No. & Grams YEAST & Fermented: $31 / 2$ hrs. $41 / 2$ hrs. & $51 / 2$ hrs. \\
193 (control) & 12.0 & 1695 & 1735 & 1745 \\
198 & $9.0(25 \%$ less) & 1805 & 1815 & 1875 \\
194 & $8.4(30 \%$ less) & 1665 & 1755 & 1795 \\
196 & $7.8(35 \%$ less) & 1655 & 1705 & 1805 \\
197 & $7.2(40 \%$ less) & 1645 & 1695 & 1795
\end{tabular}

It is obvious that the amount of yeast that can be saved by the use of ammonium sulfate depends upon the length of time the dough is fermented. In a $4^{1 / 2}$-hr. dough $\left(4^{1 / 2}\right.$ hrs, is the time adopted in many bakeries for straight doughs), 30 per cent of the usual amount of yeast can be saved, while the saving in yeast in a $5^{-1 / 2}$-hr. dough is 40 per cent. Various processes are in use in different bakeries and the length of the fermentation period ranges from $3 \frac{1}{2}$ hrs. to 6 or even $8 \mathrm{hrs}$. in straight doughs and from 5 to 10 or I 2 hrs. in the sponge-dough process. The fact that the ammonium salt accelerates the activity of the yeast most toward the end of the fermentation period is considered significant. It is then that gas production is most essential, for it causes the loaves to "spring" or "kick," which is very desirable and 
necessary for the production of a loaf with a fine close texture, good color and flavor. Especially is the "spring" desirable in the special types of loaves which are cut lengthwise, for it opens and ventilates them properly and gives to the top of the loaves a fine shredded appearance that is inviting and appealing to the sight and taste. In referring to good color here, it must be borne in mind that excessive fermentation will destroy such good color, as is reasonable to expect, dependent on the grade or quality of flour used, while proper fermentation will save or spare it.

Other ammonium salts than the sulfate may be used with equally good results. We have employed the chloride, phosphate, biphosphate, tartrate, oxalate, nitrate, acetate, formate, iodide, and sulfocyanate, and have observed no pronounced differences. However, for economic reasons, the sulfate and chloride are considered most suitable for commercial purposes. Because of its alkaline properties, ammonium carbonate can not be used successfully, as is shown by the following baking experiments:

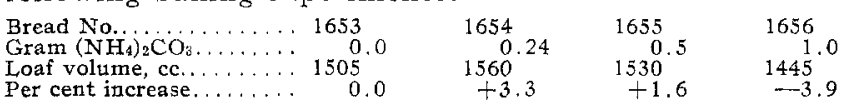

In small quantities, the volume remains practically unchanged, while it is diminished by I g. or more. Alkalies are very detrimental in bread and this, no doubt, explains the inefficiency of ammonium carbonate. Moreover, it was observed that ammonium carbonate imparted an objectionable odor to the bread. The carbonate may be used successfully only when sufficient acid is used to neutralize its alkalinity.

Ammonium fluoride accelerates the fermentation quite as much as other ammonium salts if used in small quantities; but in larger quantities it retards fermentation to a marked extent, as is evident from the following series of experiments:

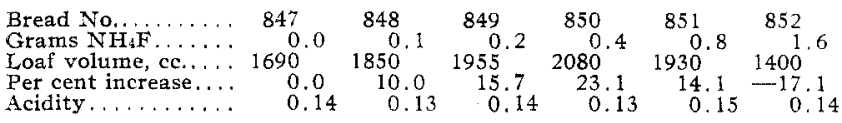

Evidently ammonium fluoride can not be used in as large quantities as ammonium sulfate, for, with the latter, the maximum acceleration was not exceeded even when $4.5 \mathrm{~g}$. were used, while with the fuoride the maximum effect was obtained with less than $\mathrm{I} g$.

In small quantities, however, the acceleration by ammonium fluoride is more pronounced, in equal weights, than that by ammonium sulfate, the explanation of which, no doubt, lies in the great difference in the molar weights. The inhibiting effect characteristic of ammonium fluoride in large quantities was also noted with hydrofluoric acid. Three doughs of the usual size were made with respectively 1,2 and $4 \mathrm{cc}$. of hydrofluoric acid solution and none of them rose. Sodium fluoride is not so detrimental, as may be seen from the following results:

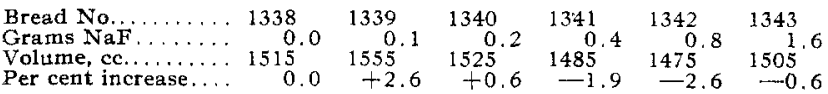

The diminution in volume observed in this series is not significant.

\section{CALCIUM SALTS}

The results of our experiments with calcium salts, which have already been mentioned in connection with their occurrence in natural waters, will now be taken up in detail. Their effect will be given both when used alone and in conjunction with other salts. The effect of calcium chloride is indicated in the following table:

\begin{tabular}{|c|c|c|c|c|c|c|}
\hline$\ldots$ & $\begin{array}{r}609 \\
0 \\
1830 \\
0 \\
348\end{array}$ & $\begin{array}{c}610 \\
0.5 \\
1935 \\
5.7 \\
361\end{array}$ & $\begin{array}{c}611 \\
1.5 \\
2040 \\
11.4 \\
380\end{array}$ & $\begin{array}{r}012 \\
2.5\end{array}$ & $\begin{array}{c}613 \\
3.5 \\
2090\end{array}$ & 6 \\
\hline
\end{tabular}

There was a decided increase in volume and gas production with the increase in the calcium chloride content of the doughs. The texture, flavor, and general appearance of the bread were improved, as well. The loaf volume was increased considerably more than the gas production, which would indicate that calcium chloride has an effect upon the gluten of the dough as well as upon the yeast. In the light of some experiments conducted by Hardy upon the effect of electrolytes on the strength of wheat flour, this seems highly probable.

The effect of calcium chloride upon the fermentation of cane sugar is shown in the table below. In each of the six experiments, roo g. of water, Io g. of sugar, and $2 \mathrm{~g}$. of yeast were used.

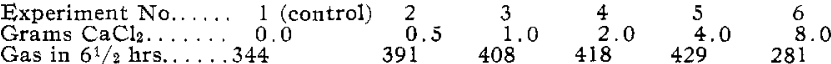

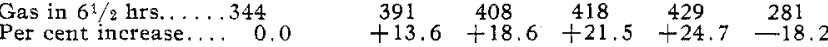

The accelerating effect of calcium chloride in bread, like that due to ammonium salts, can best be taken advantage of by reducing the amount of yeast ordinarily used. As with the use of ammonium salts, the amount of yeast that can be saved depends upon the length of the fermentation period. In a $4^{1 / 2}$-hr. dough, about 25 per cent of the yeast can be saved.

The effect of other calcium salts is very similar to that of the chloride. The results given below with calcium bimalate indicate that it is equally effective.

$\begin{array}{ccccccc}\text { Bread No......... } 573 & 574 & 575 & 576 & 577 & 578 \\ \text { Grams calcium bi- } & & & & & & \\ \text { malate........... } & 0.0 & 0.5 & 1.5 & 2.5 & 3.5 & 4.5 \\ \text { Loaf volume, cc...... } 1770 & 1850 & 1970 & 2005 & 2020 & 2110 \\ \text { Per cent increase.... } & 0.0 & 4.5 & 11.3 & 13.3 & 14.1 & 19.2\end{array}$

The increase in volume is even greater than with calcium chloride. However, as calcium bimalate is slightly acid, the two salts are not strictly comparable.

The sulfates of calcium in the following series of experiments, in which $\mathrm{CaSO}_{4} \cdot 2 \mathrm{H}_{2} \mathrm{O}$ and $\mathrm{CaSO}_{4} \cdot{ }_{1} \mathrm{H}_{2} \mathrm{O}$ were compared in molar quantities, increased the volume rather less than the chloride, especially with the larger quantities.

\begin{tabular}{|c|c|c|c|c|}
\hline $\begin{array}{l}\text { BREAD } \\
\text { No. }\end{array}$ & $\underset{\mathrm{CaSO}_{4} 2 \mathrm{H}_{2} \mathrm{O}}{\text { Grams }}$ & $\underset{\mathrm{CaSO}_{4}, 1 / 2 \mathrm{H}_{2} \mathrm{O}}{\text { Grams }}$ & $\begin{array}{l}\text { IOAF } \\
\text { Cc. }\end{array}$ & $\begin{array}{l}\text { Volume } \\
\% \text { Increase }\end{array}$ \\
\hline 3916 (control) & 0.0 & 0.0 & 1670 & 0.0 \\
\hline 3917 & 0.5 & 0.0 & 1710 & 2.4 \\
\hline $\begin{array}{l}3918 \\
3919\end{array}$ & $\begin{array}{l}0.0 \\
1.0\end{array}$ & $\begin{array}{l}0.422 \\
0.0\end{array}$ & $\begin{array}{l}1723 \\
1726\end{array}$ & $\begin{array}{l}3.2 \\
3.4\end{array}$ \\
\hline $\begin{array}{l}3919 \\
3920\end{array}$ & $\begin{array}{l}1.0 \\
0.0\end{array}$ & 0.844 & $\begin{array}{l}1 / 20 \\
1796\end{array}$ & $\begin{array}{l}3.4 \\
7.6\end{array}$ \\
\hline 3921 & 2.0 & 0.0 & 1863 & 11.5 \\
\hline 3922 & 0.0 & 1.688 & 1826 & 9.4 \\
\hline 3923 & 4,0 & 0.0 & 1830 & 9.6 \\
\hline 3924 & 0.0 & 3.376 & 1853 & 11.0 \\
\hline 3925 (control) & 0.0 & 0.0 & 1676 & 0.4 \\
\hline
\end{tabular}

In the following series of experiments the sulfate 
and chloride were compared carefully, using small quantities:

$\begin{array}{cl}\begin{array}{c}\text { BREAD } \\ \text { NO. }\end{array} & \text { GRAMS SALTS } \\ 1060 & 0.0 \\ 1061 & 1 \mathrm{CaCl}_{2} \\ 1062 & 1 \mathrm{CaSO}_{4} 1 / 2 \mathrm{H}_{2} \mathrm{O} \\ 1063 & 2 \mathrm{CaCl}_{2} / \mathrm{CaSO}_{4 .} 1 / 2 \mathrm{H}_{2} \mathrm{O}\end{array}$

$\begin{array}{lc}\text { LOAF VOLUME } \\ \text { Cc. } & \text { \% Increase } \\ 1830 & 0.0 \\ 1915 & 4.6 \\ 1945 & 6.2 \\ 2045 & 11.7 \\ 2065 & 12.6\end{array}$

In each case it will be noticed that the sulfate gives a slightly larger loaf volume. In small quantities, then-say, about $2 \mathrm{oz}$. per $60 \mathrm{lbs}$. of water, or approximately $\mathrm{I} 60 \mathrm{lbs}$. of bread-the sulfate gives equally good, if not better results than the chloride. In practice there is used not more than 2 oz. per I6o lbs. of bread and as calcium chloride, owing to its extremely hygroscopic nature, can not be used satisfactorily, because it can not be conveniently shipped or kept in the dry state, the sulfate is preferable for commercial use.

The ritrate and phosphates of calcium have also been used successfully. Of the phosphates, $\mathrm{Ca}\left(\mathrm{H}_{2} \mathrm{PO}_{4}\right)_{2}$ and $\mathrm{CaHPO}_{4}$ are most suitable, as the normal salt is both alkaline and diffictulty soluble.

Since both calcium and ammonium salts accelerate fermentation and improve bread, experiments were made with both salts in conjunction with breadmaking. The results of one series of experiments were:

$\begin{array}{ccccc}\text { BREAD } & \begin{array}{c}\text { Gram } \\ \text { No. }\end{array} & \begin{array}{c}\text { Grams } \\ \left.\mathrm{NH}_{4}\right)_{2} \mathrm{SO}_{4}\end{array} & \begin{array}{c}\text { LOAF } \\ \text { CaCl. }\end{array} & \begin{array}{c}\text { Cc. } \\ \% \text { Increase }\end{array} \\ 548 \text { (control) } & 0.0 & 0.0 & 1800 & 0.0 \\ 549 & 0.5 & 0.0 & 1800 & 0.0 \\ 550 & 0.5 & 0.5 & 1985 & 10.1 \\ 551 & 0.5 & 1.5 & 2050 & 13.9 \\ 552 & 0.5 & 2.5 & 2065 & 14.7 \\ 553 & 0.5 & 3.5 & 2115 & 17.5 \\ 554 & 0.5 & 4.5 & 2120 & 17.7\end{array}$

Thirty per cent less yeast was used with these salts. It will be seen that in conjunction with ammonium sulfate calcium chloride gives a further increase in the loaf volume. Since this was found to be true, a series of experiments was made to determine how much yeast could be saved by the use of both salts in bread. The results were as follows:

\begin{tabular}{|c|c|c|c|c|c|c|c|c|}
\hline DD & $\underset{\mathrm{CaCl}_{2}}{\mathrm{Grams}}$ & $\begin{array}{c}\text { Gram } \\
\mathrm{NH}_{4} \mathrm{Cl}\end{array}$ & Used & $\begin{array}{r}I \\
31 / 2 \mathbf{~ h}\end{array}$ & , & $\begin{array}{l}\mathrm{ME} \\
\vdots \\
y_{2} \text { hrs. }\end{array}$ & $\begin{array}{c}\text { Mean } \\
\text { Loaf } \\
\text { Vol. }\end{array}$ & \\
\hline a1) & 1) $\begin{array}{l}0.0 \\
0.0 \\
2.0 \\
2.0 \\
2.0 \\
2.0\end{array}$ & 两 & $\begin{array}{l}40 \% \text { less } \\
50 \% \text { less } \\
60 \% \text { less }\end{array}$ & 180 & & & & $\begin{array}{r}11.7 \\
1.8\end{array}$ \\
\hline
\end{tabular}

With both salts, as with the use of an ammonium salt alone, the amount of yeast that can be saved depends upon the fermentation period employed. After $3 \frac{1}{2}$ hrs. fermentation, only 50 per cent of the normal amount of yeast could be saved without a sacrifice in loaf volume, while after $4^{1 / 2}$ hrs. 60 per cent could be saved. After $51 / 2 \mathrm{hrs}$. fermentation, the batch with 60 per cent less yeast produced a loaf volume that was decidedly larger than the control, indicating that still more yeast could have been saved.

The fact that the gas production is greatly increased toward the end of the fermentation period by the yeast nutriments, was observed also by collecting the gas from 6o-g. portions of two doughs over a saturated solution of calcium chloride in Bunsen gas holders. The following data will serve to illustrate this point:
Gas Produced during Various Perions

$\begin{array}{lcccccccc}\text { Time } & 9: 40 & 10: 40 & 11: 40 & 12: 50 & 1: 50 & 2: 50 & 3: 50 & \text { TOTAL. } \\ \text { Control } & 0 & 55 & 67 & 85 & 89 & 74 & 77 & 447 \mathrm{cc} \text {. } \\ 1643 & 0 & 28 & 43 & 62 & 73 & 75 & 80 & 361 \mathrm{cc} .\end{array}$

It will be noticed that dough 1643 (with 50 per cent of the usual quantity of yeast, I $g$. of $\mathrm{CaCl}_{2}$ and $0.5 \mathrm{~g}$. of $\left.\left(\mathrm{NH}_{4}\right)_{2} \mathrm{SO}_{4}\right)$ evolves gas only about half as rapidly as the control in the initial fermentation, but that after $6 \mathrm{hrs}$. it exceeds the control in the rate of gas production. This is indeed significant, for it is at the end of the fermentation period when the dough has been moulded into loaves that active production of gas is required and most needed. If the yeast weakens when the dough is in the proof box or oven, the bread will not have the "spring" necessary to produce a well-risen loaf with a good shape and texture.

In this connection, it should be mentioned that others have experimented with ammonium salts in connection with research on fours. J. T. Willard and C. O. Swanson ${ }^{1}$ found that ammonium chloride produced a beneficial effect on the baking qualities of flour, while the phosphate had no effect, and the tartrate and acetate had a detrimental effect upon the texture. The application of ammonium chloride or other ammonium salts to effect economies in yeast in connection with bread-making are not mentioned in the report of those investigators.

A. J. J. Vandervelde, L. Bosmans, F. Le Perre, J. Mason and $A$. Revigu ${ }^{2}$ state that ammonium chloride and nitrate have only a slight action and that calcium nitrate exerts a very unfavorable action. In our opinion, the quantities used were excessive, and, moreover, such discrepancies in the literature on bread are not uncommon and are to be explained, no doubt, by inaccuracy in experimentation and by the fact that so many factors, such as temperature, age of dough, strength of flour, stiffness of dough, etc., affect the results; consequently, they are often misinterpreted and important results are sometimes overlooked.

The fact that the initial fermentation with yeast nutriments with a reduction in the usual amount of yeast is much slower than that of a normal dough has an interesting economic significance. It is well known that during the normal fermentation of bread there is a considerable loss of dry material, due to the decomposition of the constituents of the dough into volatile products. These losses as determined by various investigators are: Voorhees, ${ }^{3} 4.3$ per cent; Heeren, I.57 per cent; Fehling, ${ }^{3}$ 4.2 I per cent; Croeger, ${ }^{3}$ 2.1 4 per cent; Jago, ${ }^{4}$ 2.50 per cent; and Snyder and Voorhees, ${ }^{5} 2$ to 6 per cent or even I I per cent, in cases of prolonged fermentation.

One of us, in a previous paper, ${ }^{6}$ demonstrated that the losses in bread-making depend to a large extent upon the amount of fermentation which the dough undergoes. In a normal fermentation the losses were found to be 5.r 5 per cent, while with the same flour

1 Kansas Agr. Exper. Sta., Bull. 190, 248-251; Exp. Sta. Record March, 1912,356

${ }^{2}$ Rev. gén. chim., 16, 123,136.

${ }^{3}$ U. S. Dept. Agr.. Office of Experiment Stations, Bull. $\mathbf{3 5 .}$

4 Jago, "The Science and Art of Bread-Making," p. 361

5 U. S. Dept. Agr., Bull. 67, 11 and 28.

Gohman, Trrs Journal, $4(1912), 20-30$ and 100-106. 
the total losses were only r.8 r per cent; when the loaves were placed into pans at once upon mixing. The bread obtained in this way was decidedly poor, as is always the case when it is very much underfermented, and it was made in this way merely to detect any difference in losses due to fermentation. In salt-rising bread the losses were found to be only 0.44 per cent. This difference in the losses in the two types of bread was explained as follows: (I) Yeast produces I.04 parts of alcohol for every part of carbon dioxide, both of which are largely driven off during the process of baking, while in salt-rising bread there is no alcohol produced. (2) It is necessary to ferment yeast bread in the sponge and dough stages from 5 to $8 \mathrm{hrs}$., and, as it is allowed to rise in loaf form in the pans but one hour or less, only a small part of the total gas produced is actually used in aeration, while salt-rising bread is made into loaves and placed in the pans immediately upon mixing the dough and very little gas is lost. (3) The gases produced by yeast consist of carbon dioxide, while those produced by the salt-rising bacterium consist of about $1 / 3$ carbon dioxide and $2 / 3$ hydrogen, which is only $1 / 22$ as heavy as the former.

The fact that the losses in ordinary bread are dependent upon the amount of fermentation led us to suspect that with the use of yeast stimulants the decomposition of sugar would be less than in a normal dough, because the initial fermentation is much slower and the total gas production is less. With this idea in mind, we made three normal doughs and three with a reduction of 50 per cent in the usual amount of yeast and with $0.5 \mathrm{~g}$. ammonium sulfate and $\mathrm{r.2} \mathrm{g}$. calcium chloride in I000 $\mathrm{g}$. of flour. The gas evolved in the usual time from 50-g. portions of the doughs was collected in Bunsen gas holders, and from the total weight of gas produced the quantity of sugar decomposed was calculated, assuming that the carbon dioxide evolved represented 45 per cent of the loss in sugar. The results of these experiments are given below:

\begin{tabular}{|c|c|c|c|c|c|}
\hline \multicolumn{2}{|c|}{ BREAD No. } & \multicolumn{2}{|c|}{ CC. GAS FORMED } & \multicolumn{2}{|c|}{$\begin{array}{l}\text { PER CENT LOSS IN SUGAR } \\
\text { Calculated on Flour }\end{array}$} \\
\hline Controls & $\begin{array}{l}1135 \\
1137 \\
1139\end{array}$ & $\begin{array}{l}396 \\
404 \\
409\end{array}$ & Av. 403 & $\begin{array}{l}4.25 \\
4.34 \\
4.39\end{array}$ & Av. 4.33 \\
\hline $\begin{array}{l}\mathrm{NH}_{4} \mathrm{Cl} \\
\text { and } \\
\mathrm{CaCl}_{2}\end{array}$ & $\begin{array}{l}1136 \\
1138 \\
1140\end{array}$ & $\begin{array}{l}333 \\
353 \\
348\end{array}$ & Av. 345 & $\begin{array}{l}3.58 \\
3.79 \\
3.94 \\
\text { DIFFE }\end{array}$ & $\begin{array}{l}\text { Av. } 3.70 \\
\text { NCE } 0.63\end{array}$ \\
\hline
\end{tabular}

It will be noticed that the consumption in sugar is considerably higher in the control dough than in the one with added salts. The difference represents the saving in sugar that is effected by the use of ammonium and calcium chlorides in bread.

\section{USE OF POTASSIUM BROMATE}

In connection with the use of these salts as yeast nutriments in bread-making, with special reference to the losses, mention will be made briefly of potassium bromate as used in conjunction with them. The functions of the latter salt will be more fully treated in a subsequent paper, inasmuch as it is not a yeast nutriment but acts upon the dough, imparting to it very desirable properties.

In the fermentation of bread, a twofold object is accomplished; namely, the maturing, or aging, of the dough, and the aeration of the bread. The former is accomplished during the fermentation period, which takes from 4 to $6 \mathrm{hrs}$. in the best practice, and the latter during the proofing period, which requires from $1 / 2$ to I hr. After the dough is sufficiently matured, or aged, it passes through the dividing and moulding machines, which press out practically all of the gas. Then it is put into pans and allowed to proof, and only the small fraction of the total gas which is produced while the bread is in the pans actually functions in aerating the bread. The effect of the potassium bromate upon the dough is essentially an aging, or maturing, effect and is characterized by the exceedingly small quantities required. The following series of experiments will serve to illustrate the changes in loaf volume with increasing quantities of potassium bromate:

$\begin{array}{lrrrrr}\text { Bread No........... } & 4547 & 4548 & 4549 & 4550 & 4551 \\ \text { Gram potassium brom- } & & & & & \\ \text { ate............... } & 0.000 & 0.015 & 0.030 & 0.060 & 0.120 \\ \text { Loaf volume, cc....... } & 1735 & 1785 & 1755 & 1605 & 1375 \\ \text { Per cett increase....... } & 0.0 & +218 & +1.1 & -7.4 & -21.3\end{array}$

The maximum volume occurs with $0.0 \mathrm{I} 5 \mathrm{~g}$. per batch of $1000 \mathrm{~g}$. of flour, and it will be noticed that with 0.06 and especially with $0.120 \mathrm{~g}$. there is a marked diminution in volume. This influence upon the loaf volume is not due to any change in the rate of fer. mentation or gas production, but to the pronounced aging, or maturing, effect of the salt upon the dough itself. Similar changes in volume are effected by varying the amount of fermentation to which the dough is subjected. Up to a certain point, the gasretaining power of dough and the loaf volume are increased by fermentation; then the dough becomes "rotten," $i$. e., it no longer retains the gas well and, accordingly, the volume is greatly reduced.

A desirable quantity of potassium bromate-say $0.015 \mathrm{~g}$. per batch of dough containing $600 \mathrm{~g}$. of waterages the dough so decidedly that 25 or 30 per cent of the usual amount of yeast can be saved without imparting to the bread any of the characteristics of underfermentation, such as heaviness, dark color and coarseness in texture. In fact, the bromate in these quantities improves the bread with respect to texture even though the yeast is reduced by 25 per cent. This pronounced effect is attributed to the oxidizing power of this salt, for it has been found that by passing oxygen through the dough a similar maturing action is obtained, but to a lesser degree. This is probably due to the condition of the oxygen-in one case we have molecular oxygen and in the other we have nascent oxygen-the nascent oxygen being more powerful than the molecular, and, therefore, would have a greater maturing action on the dough. The effectiveness of the nascent oxygen is indeed surprising, for the quantity of the potassium bromate is so small that the total available oxygen is less than $\mathbf{I} \mathrm{cc}$. per loaf of bread.

When potassium bromate is used in addition to ammonium and calcium salts, it effects a saving in yeast of 25 to 30 per cent of the amount required without it. For instance, when jo per cent of the usual 
amount of yeast can be saved with the yeast stimulants, the saving may be increased to 65 per cent with the addition of potassium bromate.

The aging, or maturing, effect of potassium bromate upon the dough, without increasing the rate of fermentation or the sugar consumption by the yeast, results in a much greater saving in sugar than that due to the yeast stimulants alone.

To determine this saving, three normal doughs were made and three with $0.5 \mathrm{~g}$. ammonium sulfate, I. 2 g. calcium chloride, and $0.015 \mathrm{~g}$. of potassium bromate in $1000 \mathrm{~g}$. of flour and 35 per cent of the usual quantity of yeast. The gas evolved from $50 \mathrm{~g}$. portions of the doughs was used as the basis for calculating the losses in sugar due to fermentation. The results of these experiments may be thus summarized:

\begin{tabular}{|c|c|c|c|c|c|}
\hline \multicolumn{2}{|c|}{ BrEAd No. } & \multicolumn{2}{|c|}{ CC. GAS FORMED } & \multicolumn{2}{|c|}{$\begin{array}{l}\text { PER cent Loss in SUGAR } \\
\text { Calculated on Flour }\end{array}$} \\
\hline Controls & $\begin{array}{l}2237 \\
2238 \\
2239\end{array}$ & $\begin{array}{l}415 \\
452 \\
452\end{array}$ & Av. 440 & $\begin{array}{r}5.64 \\
6.15 \\
6.15\end{array}$ & Av. 5.98 \\
\hline $\begin{array}{l}\text { New } \\
\text { Process }\end{array}$ & $\begin{array}{l}2240 \\
2241 \\
2242\end{array}$ & $\begin{array}{l}225 \\
267\end{array}$ & Av. 266 & $\begin{array}{l}3: 62 \\
3.62\end{array}$ & Av. 3.62 \\
\hline
\end{tabular}

The results of a similar series of experiments are tabulated below; these show the losses at the end of 5,6 and 7 hrs., respectively.

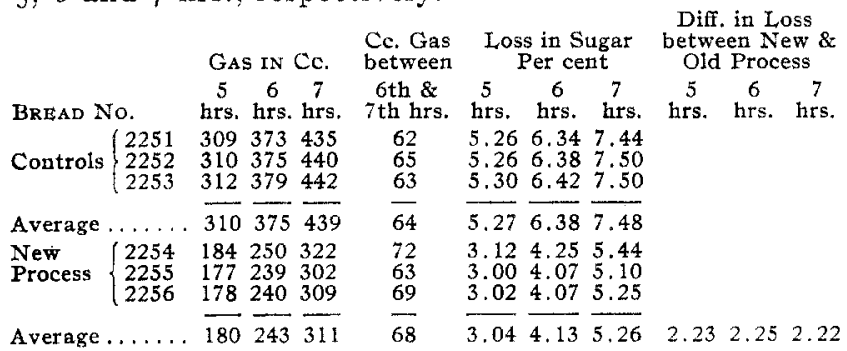

Six hours' fermentation is the approximately normal period in the best baking practice, $5 \mathrm{hrs}$. in the dough state and $\mathrm{I}$ hr. after the bread is made up into loaves. The range between 5 and 7 hrs. fermentation will cover most variations in baking processes, due to the requirements of different flours and the type of bread desired. It is clear from the results cited above that the losses increase as the fermentation proceeds and that they are uniformly lower in the new process. The differences in the average losses between the two processes are $2.23,2.25$, and 2.22 per cent in 5,6 and 7 hrs., respectively, which is practically a constant. This is to be explained by the fact that after $5 \mathrm{hrs}$. the rate of fermentation in the two processes is practically the same. The difference in decomposition of sugar occurs mostly in the initial stages of the fermentation before the nutriments greatly accelerate the activity of the yeast.

In another series of experiments, the losses were determined by direct weighing, as had previously been done by one of us, ${ }^{1}$ and also by collecting the gas. Both batches were set with $1000 \mathrm{~g}$. of flour, and, after mixing, were divided into two equal portions. Onehalf was used for the determination of the losses by weighing and from the other half three portions of $40 \mathrm{~g}$. each were taken by collecting the gas. The

Lohman, Loc. cit. results given in the following table represent the mean of the three results obtained:

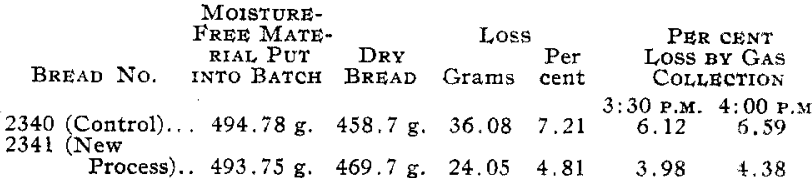

The losses ${ }^{1}$ were calculated from the gas collected at $3: 30$ o'clock, when the bread was put into the oven, and again at 4:00 o'clock, when it was taken out. The fermentation was completely arrested between the two times, of course, and the results obtained by direct weighing can more strictly be compared with those calculated on the gas at $4: 00$. Rather lower results were obtained by collecting the gas than by direct weighing. The solution of gas in the liquid of the dough may in part account for this and it is also suggested that the losses may not be due entirely to the decomposition of sugar by the yeast. However, the agreement is fairly close, showing that most of the material lost is due to the destruction of sugat by the yeast.

Sugar analyses were made of breads prepared with and without added salts and the results afford additional confirmation of the destruction of sugar by the yeast. Three batches were made, one each by the two processes with the regular amount of sugar and one by the new process with 2.25 per cent less sugar (calculated on the flour), which represents the difference in'sugar consumption by the two processes, as determined by collecting the gas. The results follow:

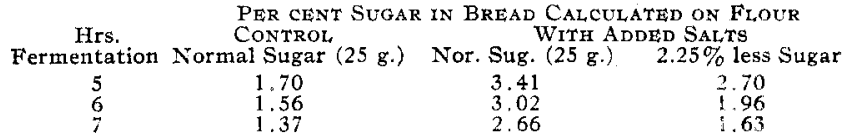

It will be noticed that with the normal amount of sugar and added salts the bread is much richer in this substance than the control, while if 2.25 per cent less sugar is used in the batch, the bread is slightly richer in sugar than the control bread.

To confirm the reduction in the destruction of fermentable material in bread by the use of the new process, gas-collection experiments were conducted in a. large bakery where it is in operation. Three portions of $50 \mathrm{~g}$. were taken from each of the two doughs ( $1600 \mathrm{lbs}$.) set by the new and old process, respectively. The losses, representing the mean of the three determinations, were as follows:

$\begin{array}{cc}\text { Par caNT Loss SugAR } \\ \text { New Process } & \text { Old Process } \\ 0.24 & 0.39 \\ 0.43 & 0.69 \\ 0.55 & 0.97 \\ 0.69 & 1.27 \\ 0.82 & 1.58 \\ 1.10 & 1.96 \\ 1.38 & 2.36 \\ 1.64 & 2.68 \\ 1.84 & 3.13 \\ 2.25 & 3.48 \\ 2.49 & 3.85 \\ 2.81 & 4.18 \\ 3.03 & 4.35\end{array}$

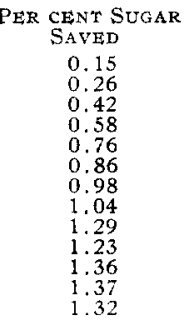

$$
\begin{gathered}
\text { Trme } \\
\text { Hours } \\
14 / 9 \\
24 / 2 \\
34 / 2 \\
3^{1 / 2} \\
4^{4 / 2} \\
4^{1 / 2} \\
5^{1 / 2} \\
5^{1 / 2} \\
6^{1 / 2} \\
7^{1 / 4}
\end{gathered}
$$

The difference in the destruction of sugars in these

1 It is assumed that the carbon dioxide represents 45 per cent of the sugar destroyed by the yeast. 
experiments was 1.37 per cent at the time the bread was removed from the oven, which was considerably less than that obtained in the laboratory. This, we think, is due to the fact that less yeast in proportion to the dough batch is required in the bakery. It is common practice to use about twice as much yeast in laboratories as is required in bakeries to mature dough in the same time. This is to be explained in part, at least, by the fact that a batch of 1600 lbs. rises from 3 to $6^{\circ} \mathrm{C}$. in temperature, due to the fermentation, while a small batch containing $1000 \mathrm{~g}$. of flour remains practically constant in temperature. The authors have frequently observed a difference in temperature of 5 to $6^{\circ} \mathrm{C}$. between the center and outside of a large dough batch. This is attributable, no doubt, to the evaporation of water on the surface of the dough, as the temperature of the room is the same as that of the dough at the time of its setting; naturally, then, the cooling effect will be much more pronounced in the case of a small dough. The small amounts of dough (50 g.) taken for collecting the gas from the large mass of $1600 \mathrm{lbs}$. in the bakery, would be especially subject to this cooling effect. Hence, we are inclined to regard the results obtained in the laboratory as nearer the truth than those obtained in the bakery, particularly when it is common knowledge that much higher proportions of yeast are required in laboratory batches.

The curves in Fig. I illustrate graphically the losses in bread-making due to the destruction of sugar. By means of the curves, the losses can be calculated at any desired time, which is impossible in determining the losses by direct weighing. In connection with the determination of the losses in bread-making, it should be mentioned here that the method involving the collection of the gas given off from an aliquot portion of the dough batch is novel.

An attempt was made to estimate the consumption of the sugars in bread by making sugar determinations upon the dough at intervals as the fermentation proceeded. Such determinations were made upon largescale doughs set both by the old and new processes. Sugar determinations were also made upon sample loaves of bread that were taken from the batches at intervals and allowed to rise to the usual height in the pans and baked. The results are given in the following table:

\begin{tabular}{|c|c|c|c|c|c|c|c|}
\hline & & CENT & UGAR & $T E D$ & $\begin{array}{l}F_{L O} \\
-B\end{array}$ & & \\
\hline Tix & $\begin{array}{l}\text { Old } \\
\text { Process }\end{array}$ & Tis & & Time & $\begin{array}{c}\text { Old } \\
\text { Process }\end{array}$ & Time & $\begin{array}{c}\text { New } \\
\text { Process }\end{array}$ \\
\hline 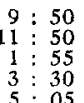 & $\begin{array}{l}5.21 \\
5.67 \\
5.22\end{array}$ & $\begin{array}{r:l}9: & 30 \\
11: & 40 \\
1: & 30 \\
3: & 05 \\
4 & 55\end{array}$ & $\begin{array}{l}4.72 \\
5.16 \\
5.44 \\
5.29 \\
4.88\end{array}$ & $\begin{array}{r}12: 00 \\
1: 10 \\
3: \\
5: 00\end{array}$ & $\begin{array}{l}5.32 \\
5.14 \\
4.12 \\
3.47\end{array}$ & $\begin{array}{l}1: 10 \\
2: 25 \\
3: 50 \\
4: 45\end{array}$ & $\begin{array}{l}4.82 \\
4.58 \\
4.35 \\
4.22\end{array}$ \\
\hline
\end{tabular}

It is interesting to note that for several hours there is an increase in the sugar content of the dough, the old process reaching a maximum about 2 hrs. after the dough is set and the new one at about $4 \mathrm{hrs}$. In the light of this fact, it is evident that sugar analyses upon dough can not serve as an index to sugar consumption by the yeast. The results are of interest, however, in demonstrating the activity of diastatic enzymes. In the new process the sugar content is higher at the end of the fermentation period than at the beginning, showing that the production of sugar is greater than the consumption; in the old process, this does not obtain, as there is nearly I per cent less sugar at the end. The difference in the sugar content between the two doughs at the beginning is due to the fact that less sugar is regularly used in the new process.

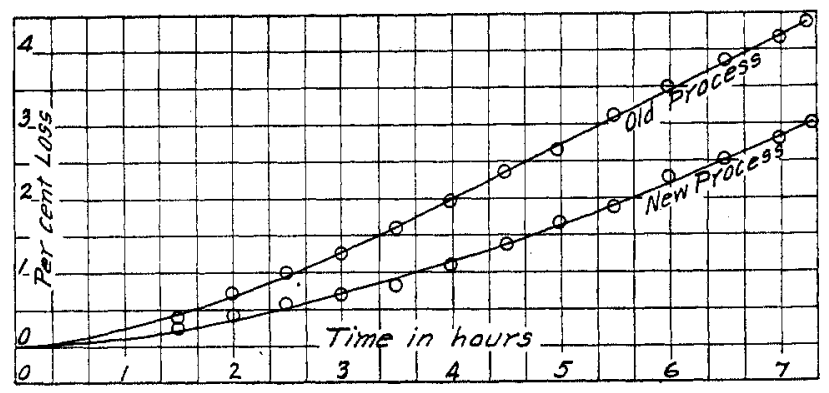

Fig. I-Loss in Bread-Making Calculated from COz Evolved

The curves in Fig. II present graphically the changes in sugar content of the doughs during the fermentation period. As the curves cross, it is demonstrated clearly that although I per cent less sugar was used in the new process, the bread baked after the usual fermentation period was actually about I per cent richer in sugar than that made by the old process.

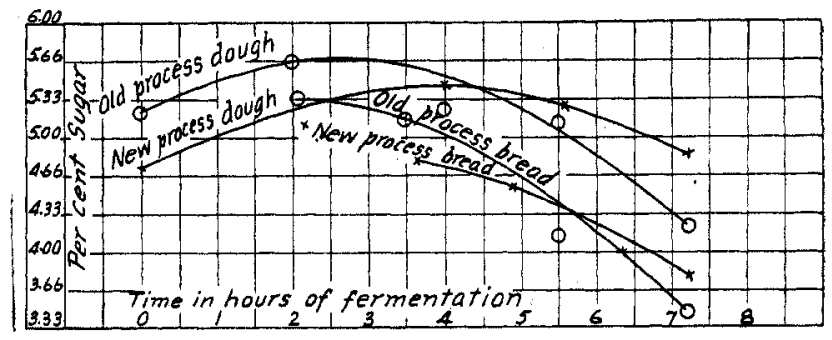

Fig. II-Changes in Sugar Content

The economic saving possible by the proper use of nutrient salts, in the advent of a rather general adoption, sums up to surprising figures. Take, for example, the saving in sugar on the average flour production of the State of Kansas-say 20 million barrels, or nearly 4 billion pounds. A saving of 2 per cent on this amount is 80 million pounds; and it is mainly sugar that is decomposed and thus lost in bread-making. The economies in the yeast are greater than those in the sugar, Even a moderate use of such a process means a considerable saving to the country and is a step towards conservation of resources. At the present time, this process is used commercially in the manufacture of more than a million loaves daily.

A further advantage incident to this process of breadmaking was observed in the increased stability and stiffness of the dough. To one familiar with doughs this is easily discernible to the touch; it was also determined more accurately and with numerical data by means of the dough viscosimeter (see Fig. III).

The viscosimeter consists essentially of a cylinder having a graduated piston which forces the dough through an aperture at the bottom. The stiffer and more tenacious the dough, the slower is the descent 
of the piston. The time that elapses while the piston descends the distance between two chosen marks is determined by means of a stop-watch. This reading in seconds represents comparative viscosities of the doughs. In the study of flours, the authors have found the viscosimeter very valuable.

Five doughs were made, four by the new process and a control. The water content of the four doughs was varied between 60 and 63 per cent, while the control was made with 60 per cent water. The viscosities, which represent the mean of five readings and the percentage of water used, are tabulated below:

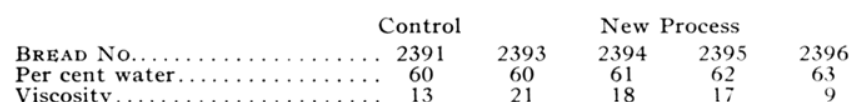

The control with 60 per cent of water is decidedly lower in viscosity than No. 2393, which has the same amount of water. It will be noticed, further, that to obtain a dough of normal stiffness and stability, from

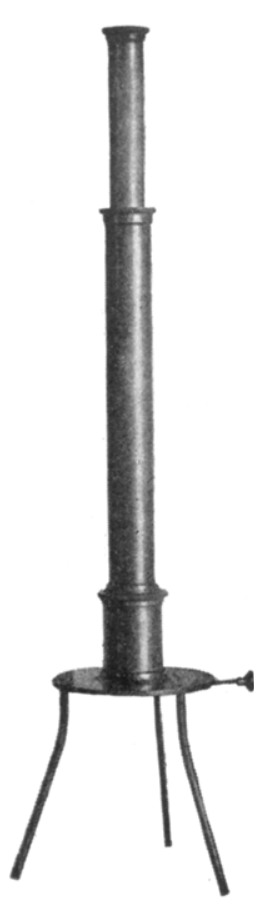

FIG. III 2 to 3 per cent more water may be added, another evidence of the conservation of flour in the dough batch from the use of these yeast foods. The resistance to softening of flour during the progress of the fermentation is of great significance in the manufacture of bread, and the greater stiffness and stability obtained by the new process is a valuable feature.

During the fermentation of the dough, the gluten is softened and partially broken down by the yeast as well as gas and alcohol being formed from the sugar. The difference in sugars decomposed between the old process and the new process is about 2 per cent when figured on the flour used. By using the new process, we are thus able to decrease the quantity of flour used by. 2 per cent and still have a dough of the same stiffness. This probably accounts for the fact that in the bakery we can use I.5 per cent more water or are able to decrease the amount of flour 2 per cent and still have a dough of the desired or usual stiffness.

The new process has been used for breads of various types, such as pan breads, Vienna and French breads; also, for rye, Graham and whole-wheat breads. Likewise, it has been used with spring, winter and Kansas flours, and the different grades of flour, and has been found to be universally applicable.

In connection with the different grades of flour, it should be said that the process can not be used to give bread the appearance of being made from a higher grade of flour than is actually employed. The improvement in color with the use of the new process is due to the improvement in texture and can not be regarded as a bleaching process. The grayish color of the lower grades of flour remains in the bread made by the new process just as it does in the usual process. By any process, the color of the crumb is improved by fermentation up to a maximum and in the new process the same changes are noted; much less yeast, however, is required to accomplish the desired results.

The practical application of the new process has met with success and it is now in operation in a large number of bakeries. A number of these are under the direction of one superintendent, who claims that the process has been of material aid in standardizing the manufacture and maintaining uniformity of the bread in the different localities. As already stated, certain differences were noticed in the bread in a chain of bakeries, although all the raw materials were identical. These have been practically overcome by the new process, which virtually standardizes the water used for the baking purposes. This would be expected, because the required nutriment is supplied by means of these salts used as yeast food, and the addition of further mineral matter, either through the water or otherwise, has less and less effect as the quantities increase. It is a general rule that, in the addition of nutriments or activators in steps, the first portion added has a correspondingly greater effect than the succeeding portions.

For the sake of convenience and accuracy in the use of these salts, they are in practice mixed with flour and salt, so that it requires $8 \mathrm{oz}$. of the mixture for $60 \mathrm{lbs}$. of water, or approximately $\mathrm{r} 60 \mathrm{lbs}$. of bread. An average bakery batch (I 200 to I 500 loaves) contains about $480 \mathrm{lbs}$. of water, which requires $4 \mathrm{lbs}$. of the yeast food, a quantity that may be conveniently weighed with accuracy. The product has also been prepared as a liquid, in which case the salts are dissolved in water, so that $8 \mathrm{oz}$. of the solution for $60 \mathrm{lbs}$. of water deliver the required amount. For the dry product the sulfate of calcium is preferred, while in the solution the chloride is used. The use of either product introduces about $2 \mathrm{oz}$. of a calcium salt, a little less than $I$ oz. of ammonium chloride and $0.02 \mathrm{oz}$. of potassium bromate into the batch for $60 \mathrm{lbs}$. of water used or for $160 \mathrm{lbs}$. of bread. In practice, the yeast food is first dissolved in the water used in the dough batch.

It is but natural to inquire: What becomes of the chemicals during the fermentation and baking of the bread? The purpose of the ammonium salt, as already stated, is to supply the nitrogen required by the yeast and it is of interest to know whether any of it remains in the bread.

The following table, showing the analyses in public laboratories of five commercial breads of greater Boston, will answer this question.

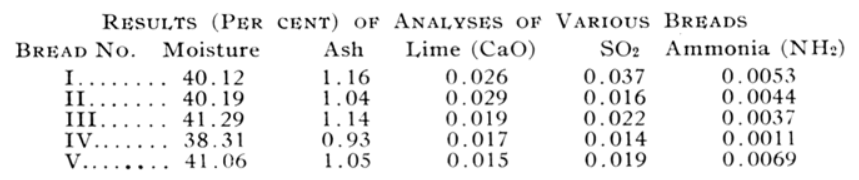

Bread No. I was made by the new process and it will be observed that it is not as high in ammonia as No. V, made without yeast nutriments. None of the breads has an ammonia content that is at all significant. 
Additional analyses in our own laboratories confirm the above results.

It will be noticed, also, that No. II is higher in lime than No. I. The state of combination of the calcium in the bread is scarcely subject to question. It has been shown by Teller ${ }^{1}$ that the phosphoric acid in flour exceeds by ten times the calcium and it may be safely said that, even by the use of the new process, the bread contains several times as much phosphoric acid as is required to combine with the calcium. Under these conditions, the potassium phosphate of the wheat undoubtedly interacts with the calcium sulfate, as it does in wort, ${ }^{2}$ in accordance with the following equations:

$$
\mathrm{KH}_{2} \mathrm{PO}_{4}+\mathrm{CaSO}_{4}=\mathrm{CaHPO}_{4}+\mathrm{KHSO}_{4}
$$$$
{ }_{2} \mathrm{~K}_{2} \mathrm{HPO}_{4}+{ }_{3} \mathrm{CaSO}_{4}=\mathrm{Ca}_{3}\left(\mathrm{PO}_{4}\right)_{2}+\mathrm{K}_{2} \mathrm{SO}_{4}+{ }_{2} \mathrm{KHSO}_{4}
$$

It is $\mathrm{known}^{3}$ that the calcium requirements of the body can be supplied by inorganic as well as by milk calcium. Abderhalden ${ }^{4}$ has demonstrated that the complicated organic substances of our foods are replaceable by the simplest structural materials and that these are built up into various tissue substances. It should be mentioned in connection with the use of calcitum salts in bread that Rudolph Emmerich and Oscar Loew ${ }^{5}$ advocate the use of calcium salts in bread from a purely dietetic standpoint. In fact, the deficiency of calcium in our food is indicated clearly in Experiment Station Record, 20, 68. A detailed discussion of this subject, with special reference to white bread, was published recently by one of us. ${ }^{6}$

The increased lime content of bread by the use of the new process is a very happy coincidence, even though incidental. Unfortunately, in modern methods of milling, the greater part of the mineral constituents of wheat is lost to white flour. As indicated by Teller, ${ }^{7}$ seven-eighths of the phosphoric acid and elevenfourteenths of the potash and lime of wheat are found in the stock feed; consequently, a partial restoration of the lime in white bread must be considered bighly desirable.

\section{CONCLUSIONS}

I-By the use of minute quantities of ammonium and calcium salts and potassium bromate in bread, from 50 to $\sigma_{5}$ per cent of the usual amount of yeast can be saved.

II-Incident to the economy in yeast thus effected, there is a saving of about 2 per cent of fermentable carbohydrates, calculated upon the total fiour used, due to the greatly diminished consumption of these by the yeast.

III-The proper use of nutrient salts for the yeast gives greater control over the dough batches and aids in the production of better and more uniform bread, regardless of the locality.

\footnotetext{
Ark. Agr. Expt. Sta., Bull. 42, 70.

"Matthews' "Manual of Alcoholic Fermentation," pp. 194 and 195.

${ }^{3}$ Biochem. Z., 9, 185-207.

Wien. med. Woch., 63, 177

s $Z$. Hygiene, 77, 311-28.

B Kohman, Bakers' Review, 31 (1914), 61-62.

7 Ark. Agr. Expt. Sta., Bull. 42.
}

IV-The added salts conserve the inherent qualities of the dough and consequently maintain its stability and strength to a far greater degree than by the old process.

$\mathrm{V}$-The finished loaves are improved in quality, flavor, texture, bloom and uniformity.

MeLion Institute

UNIVERSTTY OF PITTSBURGh

\section{A STUDY OF THE SYRUP PRECIPITATE IN WHITE SUGAR MANUFACTURE}

By Charles F. CoATes aNd L. C. Stater

Received May 9, 1916

Although the manufacture of white sugar direct from the cane has been carried on to some extent in Louisiana for nearly a century, for certain reasons this industry has lately taken on a new lease of life and at the present time is of great importance. To such a degree is this true, that most of the larger Louisiana sugar houses are now equipped for the direct manufacture of white sugar without the intervention of the bone-black refinery and in many instances have installed apparatus which has proven valuable in the manufacture of beet sugar.

The experience of the las, few years, however, would indicate that there are not only different chemical difficulties to overcome, but also certain mechanical differences in the manufacture of white granulated beet sugar and cane sugar, which make special detailed attention to the latter exceedingly necessary. For instance, leaving aside the important question of clarification, it has become evident that filtration of the clarified cane juice is imperative, but the method of filtration and the number of fi trations are points still somewhat in dispute.

Some sugar houses allow the clarified juice to settle and pass the decanted, clear juice through bag filters. Occasionally the filtered juice is filtered again before final evaporation, but ordinarily it passes direct to the effects, where it is evaporated to a Brix of from 50 to $55^{\circ}$. There is considerable difference of opinion as to the proper subsequent treatment of this syrup. Sometimes a little sulfur dioxide or phosphoric acid is added to restore the initial acidity, but usually the syrup is passed into tanks, where it is allowed to settle from 2 to $4 \mathrm{hrs}$., gradually falling in temperature during that time. When the syrup is finally drawn from the tanks, there is always to be found a precipitate, which is separated as well as possible by decantation. In certain houses the attempt has been made to filter the syrup through leaf presses. This gives a bright filtrate, but the process, being tedious and expensive, is ordinarily dispensed with, though something is always removed from the syrup. If what it removes does no harm in the subsequent manufacture of white sugar from the cane it is evident that syrup filtration could be safely omitted and the cost of manufacture lessened.

The syrup precipitate is probably not present in the solid form in the freshly evaporated syrup, inasmuch as it will form in the course of several hours in syrup which has been previously filtered, hot, through paper. 